Mohammed Saleh Antoine Vieillard-Baron

\section{On the role of left ventricular diastolic function in the critically ill patient}

Received: 16 September 2011

Accepted: 3 October 2011

Published online: 3 January 2012

(C) Copyright jointly held by Springer and ESICM 2011

M. Saleh · A. Vieillard-Baron (

Intensive Care Unit, Section Thorax-Vascular

Diseases-Abdomen-Metabolism, University Hospital Ambroise

Paré, 9 avenue Charles de Gaulle, 92104 Boulogne, France

e-mail: antoine.vieillard-baron@apr.aphp.fr

Tel.: +33-149095603

Fax: $+33-149095892$

M. Saleh · A. Vieillard-Baron

Faculté de Médecine Paris Ile de France Ouest, Université de Versailles Saint Quentin en Yvelines, 78000 Versailles, France

In the December 2011 issue of Intensive Care Medicine, Papanikolaou and coworkers [1] reported their investigation into the diagnostic performance of echocardiography in predicting the outcome of weaning, and especially the role of left ventricular (LV) diastolic function in weaning failure. The main result is presented in Fig. 2 of their study [1]. Among the 23 patients without LV diastolic dysfunction before the spontaneous breathing trial (SBT), eight failed to be weaned (35\%), whereas among the 20 patients with moderate to severe LV diastolic dysfunction, $80 \%$ failed to be weaned. In patients with mild diastolic dysfunction, 3/7 (57\%) failed. Overall, cardiogenic pulmonary edema was suspected to be the cause of weaning failing in $65 \%$ of cases [1]. The originality of the study, which renders it especially interesting, is that Papanikolaou and coworkers only included patients with preserved LV systolic function. Caille et al. [2] previously reported similar results in 117 unselected patients. In many patients, however, LV diastolic dysfunction was associated with systolic dysfunction, which is also strongly associated with weaning failure [2]. In the study by Lamia et al. [3] increase in LV filling pressures related to SBT detected by Doppler echocardiography was very predictive of weaning failure, but the population was highly selected, i.e., patients with already two failed SBTs, and around $20 \%$ of patients had a decreased LV ejection fraction.

The role of LV diastolic function in critically ill patients is probably greatly underestimated by intensivists, because it is "understudied". One of the reasons is that in the past diastolic function was difficult to evaluate at the bedside. With the development of critical care echocardiography [4]-more compact machines, improved 2D imaging, development of new indices of cardiac function, and mainly the increase in intensivists' skills in echocardiography-LV diastolic function can now be easily evaluated at the bedside in the ICU. Nagueh et al. [5] have recently published recommendations for the evaluation of LV diastolic function using echocardiography. They propose a practical and simple approach to the grading of LV diastolic dysfunction, using pulsed Doppler at the mitral valve and at the mitral annulus [5]. This classification, used by Papanikolaou et al. defines mild (grade I) dysfunction (impaired relaxation), moderate (grade II) dysfunction (impaired relaxation with mild to moderate elevation of LV filling pressures) and finally severe (grade III) dysfunction [5]. Nagueh et al. [5] also recommend performing Doppler echocardiography during exercise, a diastolic stress test, in outpatients to unmask relaxation impairment. In patients with undiagnosed myocardial relaxation impairment, echocardiography demonstrates an increase in LV filling pressure and a decrease in the relaxation time during the test [6]. Interestingly, weaning can be considered as an exercise with an increase in respiratory load, in cardiac load and in 
oxygen demand. In the study by Caille et al. [2], as in the study by Ait-Oufella et al. [7], LV relaxation was significantly shortened during the SBT. What is remarkable in the study by Papanikolaou et al. is not that grade II-III patients failed to be weaned: this was expected since they had marked elevation of filling pressures before SBT. No, it is that grade I patients also failed in 57\% of cases and that the authors demonstrated the ability of Doppler echocardiography to detect patients at high risk of weaning failure with a simple evaluation of LV diastolic function, as proposed [5].

LV diastolic function is related to myocardial relaxation, LV stiffness, and filling pressures. In the ICU, there are many situations where one or more of these factors are impaired, leading to LV diastolic dysfunction. This can be related to the patient's history (age, hypertension,...), to the disease (cardiac ischemia, arrhythmia, heart failure, pericardial disease, valvulopathy, sepsis, etc.) or to the treatment (volume resuscitation, positive end-expiratory pressure). Owan et al. [8] have reported how the prevalence of heart failure with a preserved ejection fraction has increased over a 15 -year period, representing now almost $50 \%$ of cases. However, in the ICU, we lack data from large studies regarding the incidence, characteristics, and impact on prognosis of LV diastolic dysfunction. Septic shock is a good illustration. Clinical studies have suggested an improvement in LV compliance: major for some [9], mild for others [10-12]. This may explain why severe LV systolic dysfunction is not associated with high filling pressures. But in experimental studies, as in the study by Barraud et al. [13] who used LV pressure/ volume loops, an increase in LV stiffness has been reported. Bouhemad et al. [12] have recently found isolated LV relaxation impairment (grade I of the Nagueh et al. classification) in patients with septic shock and preserved LV ejection fraction. It was associated with elevated troponin, suggesting a significant cardiac injury [12]. How it impacts tolerance to fluids remains to be elucidated.

In large clinical studies, cardiologists have extensively pointed out the impact of LV diastolic dysfunction on prognosis. For instance, increase in LV stiffness during myocardial infarction is strongly associated with heart failure and death [14]. In critically ill patients, small studies are available and more have to be done. Decrease in LV stiffness seems to improve prognosis in septic shock [9]. In a study performed in 58 mechanically ventilated patients without any history of heart failure and with preserved LV ejection fraction, Ikonomidis et al. [15] reported that patients with LV relaxation impairment, detected by Doppler echocardiography, and increased $\mathrm{N}$-terminal-pro-brain natriuretic peptide have a lower survival rate. Similar results were suggested by Sturgess et al. [16] in septic shock.

In conclusion, the study by Papanikolaou et al. sends us at least two messages. First, it says to intensivists that during the weaning process Doppler echocardiography is valuable in detecting patients at high risk for weaning failure. Second, it (re)emphasizes the importance of evaluating LV diastolic function in critically ill patients upon admission to the ICU, during their stay, and maybe also after discharge.

\section{References}

1. Papanikolaou J, Makris D, Saranteas T, Karakitsos D, Zintzaras E, Karabinis A, Kostopanagiotou G, Zakynthinos E (2011) New insights into weaning from mechanical ventilation: left ventricular diastolic dysfunction is a key player. Intensive Care Med 37:1976-1985. doi: 10.1007/s00134-011-2368-0

2. Caille V, Amiel JB, Charron C, Belliard G, Vieillard-Baron A, Vignon P (2010) Echocardiography: a help in the weaning process. Crit Care 14:R120

3. Lamia B, Maizel J, Ochagavia A, Chemla D, Osman D, Richard C, Teboul JL (2009) Echocardiographic diagnosis of pulmonary artery occlusion pressure elevation during weaning from mechanical ventilation. Crit Care Med 37:1696-1701

4. Expert round table on ultrasound in ICU (2011) International expert statement on training standards for critical care ultrasonography. Intensive Care Med 37: 1077-1083
5. Nagueh S, Appleton C, Gillebert T, Marino P, Oh J, Smiseth O, Waggoner A, Flachskampf F, Pellikka P, Evangelisa A (2009) Recommendations for the evaluation of left ventricular diastolic function by echocardiography. Eur J Echocardiogr 10:165-193

6. Ha JW, Pellikka PA, Ommen SR, Stussy VL, Bailey KR, Steward JB, Tajik AJ (2005) Diastolic stress echocardiography: a novel noninvasive diagnostic test for diastolic dysfunction using supine bicycle exercise Doppler echocardiography. J Am Soc

Echocardiogr 18:63-68

7. Ait-Oufella H, Tharaux PL, Baudel JL, Vandermeersch S, Meyer P, Tonnellier M, Dussaule JC, Guidet B, Offenstadt G, Maury E (2007) Variation in natriuretic peptides and mitral flow indexes during successful ventilatory weaning: a preliminary study. Intensive Care Med 33:1183-1186
8. Owan T, Hodge D, Herges R, Jacobsen S, Roger V, Redfield M (2006) Trends in prevalence and outcome of heart failure with preserved ejection fraction. N Engl J Med 355:251-259

9. Parker M, Shelhamer J, Bacharach S, Green M, Natanson C, Frederick T, Damske B, Parrillo J (1984) Profound but reversible myocardial depression in patients with septic shock. Ann Intern Med 100:483-490

10. Vieillard-Baron A, Schmitt JM, Beauchet A, Augarde R, Prin S, Page B, Jardin F (2001) Early preload adaptation in septic shock? Anesthesiology 94:400-406

11. Etchecopar-Chevreuil C, François B, Clavel M, Pichon N, Gastinne H, Vignon P (2008) Cardiac morphological and functional changes during early septic shock: a transesophageal echocardiographic study. Intensive Care Med 34:250-256 
12. Bouhemad B, Nicolas-Robin A, Arbelot C, Arthaud M, Féger F, Rouby JJ (2008) Isolated and reversible impairment of left ventricular relaxation in patients with septic shock. Crit Care Med 36:766-774

13. Barraud D, Faivre V, Damy T, Welschbillig S, Gayat E, Heymes C, Payen D, Shah A, Mebazaa A (2007) Levosimendan restores both systolic and diastolic cardiac performance in lipopolysaccharide-treated rabbits: comparison with dobutamine and milrinone. Crit Care Med 35:1376-1382
14. Somaratne JB, Whalley GA, Gamble GD, Doughty RN (2007) Restrictive filling pattern is a powerful predictor of heart failure events post acute myocardial infarction and in established heart failure: a literature-based metaanalysis. J Card Fail 13:346-352

15. Ikonomidis I, Nikolaou M, Dimopoulou I, Paraskevaidis I, Lekakis J, Mavrou I, Tzanela M, Kopterides P, Tsangaris I, Armaganidis A, Kremastinos DT (2010) Association of left ventricular diastolic dysfunction with elevated NTpro-BNP in general intensive care unit patients with preserved ejection fraction: a complementary role of tissue Doppler imaging parameters and NTpro-BNP levels for adverse outcome. Shock 33:141-148
16. Sturgess D, Marwick T, Joyce C, Jenkins C, Masci P, Stewart D, Venkatesh B (2010) Prediction of hospital outcome in septic shock: a prospective comparison of tissue Doppler and cardiac biomarkers. Crit Care 14:R44 